\title{
CORONARY ARTERY DISEASE: PART II
}

\author{
BY
}

\author{
M. F. OLIVER, M.D, F.R.C.P.Ed. \\ Department of Cardiology, Royal Infirmary, Edinburgh
}

\section{MYOCARDIAL INFARCTION}

\section{Early Treatment at Home}

Since most patients with acute myocardial infarction require admission to hospital, the general practitioner is primarily concerned with the relief of pain, the immediate treatment of shock, the management of acute left ventricular failure, and the start of anticoagulant therapy. In most patients pain is relieved by the intramuscular or subcutaneous injection of morphine hydrochloride or morphine sulphate $\frac{1}{4}$ gr. or $\frac{1}{2} \mathrm{gr}$. (15 or $30 \mathrm{mg}$.). When vomiting is known to follow the administration of morphine, a preparation containing the mixed alkaloids of opium (such as "omnopon") should be given intramuscularly or subcutaneously. The mild shock which often accompanies the onset of acute myocardial infarction usually responds to bed rest, warmth, and relief of pain. In contrast, persistent pain, sweating, and restlessness or a falling blood pressure indicate the need for immediate admission to hospital, since it may be necessary to combat cardiogenic shock with some of the measures outlined in the next section.

When the onset of myocardial infarction is accompanied by acute left ventricular failure " cardiac asthma"), morphine $\frac{1}{4}$ gr. (16 mg.) should be administered intramuscularly as soon as possible; it can be repeated after an hour if necessary. Cardiac asthma is an occasion when the rapid administration of digitalis is indicated. Provided the patient has not been taking digitalis in adequate dosage during the preceding week, $1 \mathrm{mg}$. of digoxin, which is dispensed in alcohol, must be given intravenously diluted in $10 \mathrm{ml}$. of sterile water. If acute left ventricular failure develops in a patient already receiving digitalis and fails to respond to morphine, intravenous digoxin should be given only with caution and preferably by small doses of $0.25 \mathrm{mg}$., repeated after an hour if no intolerance develops. The slow intravenous administration of aminophylline $500 \mathrm{mg}$. over a period of 5 minutes is sometimes valuable in cardiac asthma, but the early administration of digoxin is the treatment of choice even if a myocardial infarct is suspected. Some relief from the acute distress of left ventricular failure is likely to be evident within 20 or 30 minutes of the intravenous administration of digoxin, but the patient should not be left unattended until asleep.

The value of the early administration of anticoagulants has now been established, and when there is no known contraindication (such as an active ulcer or liver disease) the practitioner should give a soluble heparin preparation, 20,000 units intramuscularly or 10,000 units intravenously and 10,000 units intramuscularly. If there is likely to be a delay of several hours before the patient can be admitted to hospital, an initial dose of one of the oral anticoagulants, which prolong prothrombin time, such as phenindione $200 \mathrm{mg}$. (four 50-mg. tablets) or ethyl biscoumacetate $1,200 \mathrm{mg}$. (four $300-\mathrm{mg}$. tablets) can be given when the first dose of heparin is injected. Subsequent doses of the oral anticoagulants must be adjusted according to the prothrombin time.

\section{Early Treatment in Hospital}

There are several complications of acute myocardial infarction which make it desirable for the patient to be admitted to hospital. These include shock, thromboembolic incidents, left ventricular failure, and paroxysmal ventricular tachycardia or other serious arrhythmias.

\section{Cardiogenic Shock}

The hypotension of cardiogenic shock often requires vigorous treatment. Severe shock is usually resistant to therapy, and it is important to start treatment as soon as possible. Although it is often difficult to decide when to start treatment, it is a mistake to wait until the patient is grey, collapsed, sweating, apprehensive, cold, and restless with a rapidly falling blood pressure. Nevertheless, many patients who appear shocked on arrival in hospital improve rapidly after lying quietly in a warm bed for an hour. The administration of oxygen at a rate of 61 . per minute by a simple plastic mask or through a nasal catheter helps to combat the anoxaemia which accompanies cardiogenic shock.

As a broad guide, pressor drugs should be administered before the patient's blood pressure drops below 90/70. In a patient previously hypertensive, however, clinical signs of shock can develop at higher levels, and thus the blood pressure should not be the only guide. Pressor drugs, such as mephentermine sulphate $30 \mathrm{mg}$., which can be given by intramuscular or intravenous injection, are of limited value but can be administered at hourly intervals if necessary.

Noradrenaline is probably the drug of choice, though it has its disadvantages in cardiogenic shock. It must be given by intravenous infusion, $4-12 \mathrm{mg}$. in $400 \mathrm{ml}$. of isotonic saline. A suitable rate for infusion is 6-8 $\mu \mathrm{g}$. per minute. Blood-pressure readings should be recorded at intervals of 15 to 30 minutes and the rate of flow adjusted accordingly. It is desirable to maintain the blood pressure at about $110 / 80$, but it does not always respond to noradrenaline, and a pressor response is often difficult to maintain. Serious arrhythmias develop in $10 \%$ of patients. Although the treatment of shock is often disappointing, the early administration of noradrenaline may be a life-saving measure, particularly if reinforced by intravenous digoxin.

Since the administration of noradrenaline entails adding large amounts of fluid to a circulatory system whose efficiency is already impaired, the immediate risk of pulmonary oedema and congestive failure is considerable: it is all the greater if the heart has not been stimulated by digitalis. Cardiogenic shock of serious degree is invariably accompanied by signs of pulmonary congestion and by a greater or lesser degree 
of cyanosis and dyspnoea. These features indicate the prompt use of digoxin 1.0 to $1.5 \mathrm{mg}$. intravenously and suitably diluted. Alternatively, ouabain $0.5 \mathrm{mg}$. can be given intravenously in an extreme emergency, and repeated once after an hour if necessary.

\section{Thromboembolic Incidents}

The risk of further thromboembolic incidents can be reduced by the administration of anticoagulants (Gilchrist and Tulloch, 1956). If anticoagulant therapy has not already been started, then on the patient's admission to hospital 10,000 units of heparin should be given borh intravenously and intramuscularly, and 20,000 units of heparin injected intramuscularly 8 and 16 hours later. At the same time as the first dose of heparin, phenindione $200 \mathrm{mg}$. or ethyl biscoumacetate $1,200 \mathrm{mg}$. can be given orally. The dose of these anticoagulants (which are discussed in greater detail below) should be adjusted daily in order to maintain the prothrombin time between 2 and $2 \frac{1}{2}$ times the control value in seconds or the prothrombin activity between $10 \%$ and $20 \%$.

\section{Arrhythmias}

It has already been emphasized that great benefit is obtained from the intravenous administration of digoxin in acute left ventricular failure. Similarly, digitalis is valuable in the prevention of left ventricular failure and is indicated if the patient develops orthopnoea or obvious basal crepitations during recovery from an acute myocardial infarct. Digitalis is also the drug of choice for the treatment of rapid auricular fibrillation and flutter following myocardial infarction. When auricular fibrillation accompanies acute myocardial infarction, it is sometimes paroxysmal and transient, normal rhythm returning within an hour or two without any specific treatment. If, however, the ventricular rate is rapid and greater than 120 per minute, or if the paroxysm of auricular fibrillation persists for more than 2 hours, digoxın should be administered intravenously. The heart rate must be obtained from auscultation of the apex beat. since the pulse deficit which is commonly present makes its assessment at the pulse unreliable. Uncontrolled auricular fibrillation or flutter soon leads to congestive failure. The drug treatment of congestive cardiac failure has been reviewed in an earlier article in this series (Campbell, 1958).

Paroxysmal ventricular tachycardia is not common, and its occurrence should be confirmed if possible by electrocardıograms before specific remedies are employed. Although quinidine is the drug of choice, ventricular tachycardia can sometimes be corrected by the intravenous administration of procaine amide: $1 \mathrm{~g}$. of procaine amide should be diluted in $10 \mathrm{ml}$. of sterile water. and of this $1 \mathrm{ml}$. (100 mg.) can be injected each minute in the hope that normal rhythm will be promptly restored. More often paroxysmal ventricular tachycardia responds gradually to quinidine sulphate by progressive slowing in rate. Quinidine should be given in a dose of $3 \mathrm{gr} .(0.2 \mathrm{~g}$.) by mouth every 2 hours. If paroxysmal ventricular tachycardia persists after 36 hours of oral quinidine therapy, or if the patient is already developing signs of congestive failure, then the slow intravenous infusion of $3 \mathrm{~g}$. of quinidine sulphate in $500 \mathrm{ml}$. of isotonic saline is indicated: a rough guide for this infusion is to give $50-100 \mathrm{ml}$. per hour. The heart rate must be carefully watched, and electrocardiographic control at hourly or two-hourly intervals is desirable. The drug must be stopped when normal rhythm has been restored or if toxic features develop. Quinidine sulphate 3 gr. $(0.2$ g.) or procaine amide 250 mg. should be administered by mouth four times daily for several days following the correction of ventricular tachycardia.

\section{Long-term Anticoagulant Therapy}

The patient who has recovered from a recent myocardial infarct may need drugs for the treatment of angina (see Part I last week) and for the prevention of further thrombotic incidents. There is increasing evidence that the administration of anticoagulants during the first year and possibly longer after infarction lowers the rate of recurrence of further infarcts, decreases their severity, and reduces the mortality (Bjerkelund, 1957). The choice of anticoagulant will have been made when the patient is in hospital. Two are commonly used in Great Britain, phenindione ("dindevan," "indema ") and ethyl biscoumacetate ("tromexan").

Phenindione is more easily controlled, much less expensive, and is the long-term anticoagulant of choice. Its effect on prothrombin time, which is inversely proportional to the prothrombin content of the blood, is maximum in about 30 hours and has largely disappeared in about 60 hours after a single dose. This duration of activity and the lack of cumulative effect makes its administration easy to manage. It has few side-effects, but gastro-intestinal disturbances and dermatitis do occasionally occur; in these circumstances, ethyl biscoumacetate may be substituted. Tablets of phenindione contain $50 \mathrm{mg}$. and tablets of ethyl biscoumacetate contain $300 \mathrm{mg}$. ; they should be given in divided doses twice daily according to the instructions issued by the hospital or laboratory responsible for the control of the patient's prothrombin time. Oral anticoagulants should never be given unless regular and reliable estimations of prothrombin time are readily available.

Anticoagulants act indirectly by decreasing prothrombin synthesis in the liver, and there are many available anticoagulants with varying speed and duration of action. Dicoumarol (50-mg. tablets), cyclocoumarol ("cumopyran," 25-mg. tablets), and phenylpropylhydroxycoumarin ("marcoumar," 3-mg. tablets) are three coumarin derivatives which have a delayed and more prolonged effect on prothrombin time than phenindione and ethyl biscoumacetate. This cumulative effect is a disadvantage, because their action cannot be counteracted as rapidly as that of phenindione or ethyl biscoumacetate. In particular, phenylpropylhydroxycoumarin prolongs prothrombin time maximally at 5 days and still has some effect after 10 or 12 days following a single dose. The administration of these longer-acting anticoagulants is difficult to manage, and they are not recommended.

The family doctor will find these differences in duration of action worth bearing in mind, because he may need to administer phytonadione (vitamin $K_{1}$ ) in the event of a haemorrhage. Haemorrhage is not common if the dose of anticoagulant is carefully controlled by prothrombin-time estimations, though unfortunately it does occur from time to time even when the prothrombin time is within the desired therapeutic range.

Haemorrhage occurs most commonly as minor subcutaneous bruising, minor haematuria, or minor 
epistaxes and less frequently as large haematomata, haematemesis, or melaena. When phenindione or ethyl biscoumacetate are being taken, $25-50 \mathrm{mg}$. of vitamin $\mathrm{K}_{1}$ orally is usually sufficient to restore prothrombin levels to normal within 18 to 24 hours. $10-20 \mathrm{mg}$. of vitamin $K_{1}$ given intravenously will have a quicker effect, but this is seldom necessary for a minor haemorrhage, since vitamin $K_{1}$ is active within three hours of its oral administration. Indeed, since anticoagulant therapy will be continued after the haemorrhage has stopped, only the omission of the anticoagulant for one or two days is usually all that is necessary for superficial bruising. It is undesirable to administer vitamin $\mathrm{K}_{1}$ in the presence of minor bleedings, since the abrupt return of the prothrombin time to normal is sometimes associated with the development of further thrombosis. With the longer-acting coumarin derivatives, $50-100 \mathrm{mg}$. of vitamin $K_{1}$ orally or $25 \mathrm{mg}$. intravenously will be necessary in the event of a haemorrhage. If the family doctor finds it necessary to give vitamin $K_{1}$ or to reduce or stop the anticoagulant, he should refer the patient to the hospital or laboratory which is controlling the prothrombin time as soon as possible.

REFERENCES

Bjerkelund, C. J. (1957): Acta med. scand., 158, Suppl. 330. Camphell, M. (1958). Brit. med. J., 2, 1284.

Gilchrist, A. R., and Tulloch, J. A. (1956). Scot. med. J., 1, 1.

\section{THE TARDY CONVALESCENT}

BY

\section{GEORGE DAY, M.D. \\ The Mundesley Hospital}

One of the most memorable French exercises I was ever made to perform-I must have been 9 or 10 at the time-was to translate into French a little anecdote which ran thus: "A lady called upon a doctor to examine a spot on her finger. "It is a very good thing you lost no time,' he said. 'Why? Is it so very serious?' she asked. 'Had you waited until to-morrow, it would have disappeared,' he said, 'and I should have lost my fee." ("J'aurais perdu mon lolly," dit-il.)

I have always found this story very comforting; indeed, it may have unconsciously influenced my choice of profession: I don't know.

The fact is, luckily for most of us, that the animal body, the human psyche, and the divine spirit all strive to heal themselves when damaged, and to compensate themselves (in the non-litigious sense) when the damage is irreparable. This sometimes happens with our patients before we have got round to making a diagnosis. If we doctors ceased to exist, a working majority of our patients would get well of their own accord; and the human race would persist, not quite so uncomfortably overcrowded, perhaps, and not so geriatric-ridden; but it would get by. This may be the real reason why we never dare go on strike.

After the disease process has in the natural course of events burned itself out, after the physicians and surgeons have implemented such measures as stop the patient going downhill, by giving him something or taking something away, you might think that the patient would inevitably heal himself and regain a near-perfect state of health under his own steam ? Not a bit of it. He will if he is an animal-a cat will streak across the lawn on three legs after a bird before the stitches are out of his amputation stump-but not if he is a human with the normal human fear of the unknown and human suggestibility. He usually enters a stage of convalescence ; and how soon he will emerge from that stage into exuberant or subdued health depends upon several factors, of which the possession of sound wind and limb is, oddly enough, one of the least important.

Why is this? What are the forces that militate against return to full health ?

\section{Fear}

First and foremost, obviously, is fear: fear born of ignorance or incomplete comprehension. Many patients, I find, embark on their convalescence without any clear idea of what has been happening to them; what has been done for them; the whys and wherefores; and what they may expect next. And with the vast majority of them, what they fear in their imaginings is much, much worse than the truth.

A middle-aged doctor surprised me at my first interview with him, before I had even outlined a tentative policy for his rehabilitation. He had had a small patch of bronchopneumonia with great constitutional upset. He had never had a day's illness in his life, and it had shattered him. He said, "I suppose I shall have to be pretty careful from now on? My wife has brought me long-sleeved vests and pants. Good thick ones, too. Like that stuff you stand typewriters on. They are going to take some getting used to. I'm used to wearing a thin singlet and shorts summer and winter alike." It was no use arguing with the man. It had to be deeds and not words. His rehabilitation took the practical form of nine-mile tramps around the country in all weathers, bicycling, sunbathing, and swimming. It took just over a fortnight, and he left in very good heart.

Women who have been parted from a nine-pound uterus which used to bleed furiously in and out of season don't realize that its removal enables them to enjoy better health and greater activity than they have experienced for years. They are often under the impression that the operation was performed merely to prevent them from getting worse; and they expect nothing better. The same applies to some who have had radical operations for prolapse or hernias. They have been mutilated and weakened, and must therefore be very, very careful in the future.

Where did they pick up these ideas? From the surgeons? It is most unlikely, except-and I shall return to this point later-where there is an ominous uncertainty implied by the request that they should attend the out-patient department in one, two, or three months' time. They feel they had better go slow until they have had this final "all clear."

They may have got the idea partly from hospital ward discipline, which lays such emphasis on bed rest, and allows no more exertion than sitting and strolling about the ward in dressing-gowns. It is possible that the last week or so of their hospital treatment is geared too low for their actual potentialities. Ward routine demands that after a certain point they seem to make no further progress.

And then, of course, they talk among themselves and compare notes. And they certainly have much to discuss. At Mundesley their discussions are unending and terribly inconclusive, for the patients are a random 